International Journal of Fatigue

July 2016, Volume 88, Pages 247-256

http://dx.doi.org/10.1016/i.jifatigue.2016.03.033

http://archimer.ifremer.fr/doc/00324/43523/

(C) 2016 Elsevier Ltd. All rights reserved

\title{
Fatigue resistance of natural rubber in seawater with comparison to air
}

\author{
Narynbek Ulu Kubat ${ }^{1,2}$, Huneau B. ${ }^{1,{ }^{*}}$, Le Gac Pierre-Yves ${ }^{2}$, Verron E. ${ }^{1}$ \\ ${ }^{1}$ Ecole Centrale de Nantes, Institut de Recherche en Génie Civil et Mécanique (GeM), UMR CNRS \\ 6183, Nantes, France \\ 2 IFREMER, Centre de Bretagne, Marine Structures Laboratory, Brest, France \\ * Corresponding author : Bertrand Huneau, email address : bertrand.huneau@ec-nantes.fr
}

\begin{abstract}
:
Fatigue properties of filled natural rubber in seawater environment are investigated by uniaxial fatigue and crack propagation experiments, and the damage is analyzed by scanning electron microscopy. The behavior under relaxing and non-relaxing loading conditions is studied and the results are compared to those obtained in air environment. For relaxing loading conditions, fatigue behavior is the same in both environments. Under non-relaxing conditions at large strain levels, for which the influence of straininduced crystallization is important, fatigue life is longer in seawater. Such behavior could be explained by increased internal temperatures of specimens tested in air due to lower heat conductivity of air as compared to seawater. Such conclusion is also supported by the damage mechanisms observed under non-relaxing loading conditions.
\end{abstract}

\section{Highlights}

- Fatigue life and crack propagation tests are performed. Fatigue damage is analyzed by Scanning Electron Microscopy. Fatigue behavior is the same as in air under relaxing loading conditions. Fatigue life is longer in seawater under non-relaxing large strain amplitudes. - Non-classical cracking features are observed in seawater.

Keywords : Natural rubber, Fatigue, Environmental effects, Seawater, Strain-induced crystallization 


\section{Nomenclature}

6PPD N-[1,3-Dimethylbutyl]-N'-phenyl-p-phenylenediamine (antioxidant, antiozonants)

C crack length of a SENT specimen

CB carbon black

CBS N-cyclohexyl-2-benzothiazolesulphenamide (vulcanization accelerator)

$K \quad$ constant as a function of maximum stretch ratio relating tearing energy to strain energy density for SENT specimen

II deformed length

$I_{0} 10 \quad$ initial length

EDS Energy Dispersive Spectroscopy

LVDT linear variable differential transformer

NR natural rubber

SENT single-edge notched tension specimen

SEM scanning electron microscopy

SIC strain-induced crystallization

$R \quad$ loading ratio

$T \quad$ tearing energy

W strain energy density

$\lambda \quad$ global stretch ratio

$\Delta \lambda \quad$ amplitude based on maximum local stretch ratio

Nlocal maximum local stretch ratio within the specimen

$\lambda \max$ maximum amplitude based on maximum local stretch ratio

$\lambda$ min minimum amplitude based on maximum local stretch ratio 


\section{INTRODUCTION}

Natural rubber (NR) is a versatile elastomer that has been used industrially for well over a century. It has found use in many different applications mainly because of its ability to dissipate energy and undergo large elastic deformation whilst maintaining excellent resistance to crack growth. The majority of NR is used in production of automobile tires. Additionally, it finds use in the marine environment (upon a selection of appropriate formulations) because of its low water absorption and consistent mechanical properties after prolonged immersion in seawater. With recent growth of interest in off-shore energy production, ranging from oil or natural gas, wave, wind, to tidal energy, better understanding of fatigue behavior of natural rubber in seawater is of interest at present.

The study of NR fatigue is divided into two complementary approaches that lead to determination of fatigue life (Mars \& Fatemi 2002): the crack nucleation approach, which focuses on the prediction of crack initiation in a material without defects; and, the crack propagation approach, which considers the cyclic growth of an existing crack. The crack nucleation approach refers to continuum mechanics, whereas the crack propagation approach refers to fracture mechanics. Several factors influence fatigue properties of NR. In general, they are separated into three groups (Mars 2004): mechanical loading conditions, environmental conditions, and chemical formulation (addition of antioxidants, antiozonants, filler, and other additives used in the industrial process).

The mechanical loading conditions for soft materials are usually defined by prescribed displacement or strain energy density (Beatty 1964). In both cases, we classically define the $R$-ratio, or the loading ratio, as the ratio of the minimum to the maximum loading quantity. In terms of the stretch ratio $\lambda=l / l_{0}$, it is defined as:

$R=\frac{\left(\lambda_{\min }-1\right)}{\left(\lambda_{\max }-1\right)}$ 
The $R$-ratio is a useful descriptor of mechanical loading and its value considerably affects the fatigue behavior. For $R=0$, i.e. the minimum loading quantity is zero, the mechanical loading conditions are said to be relaxing; when $R>0$, i.e. the minimum loading quantity is positive, they are said to be non-relaxing. Under the latter type of loading conditions, fatigue resistance of NR improves (notably in contrast to metals). The general consensus is that presence of strain-induced crystallization (SIC) is responsible for such improvement (Lindley 1973, Gent \& Zhang 2002). The effects of SIC in fatigue will be discussed in further detail in Section 4. For further information on SIC in rubber, the reader can refer to the recent review articles of Tosaka (2007) and Huneau (2011).

The second factor that influences fatigue properties of rubber is the environment. In air, the fatigue behavior has been extensively studied: see for example Cadwell et al. (1940), Rivlin \& Thomas (1953), Lindley (1972, 1973), Lake (1995), and many others. In air, fatigue is a mechanico-oxidative process (Lake \& Lindley, 1965). Comparison with results in an oxygen free environment (nitrogen) reveals that gaseous oxygen accelerates crack growth and decreases the fatigue crack propagation threshold (Legorju-Jago \& Bathias, 2002). A study by Gent \& Hindi (1990) shows that in vacuum environment, i.e. with no exposure to oxygen, the crack propagation rate is reduced roughly by a factor of 2 as compared to air environment. Oxygen also has a long term effect on NR fatigue due to ageing, which is driven by diffusion of oxygen in NR; primarily, it affects the mechanical properties making it hard and brittle (Datta \& Huntink, 2000). For NR, ageing reduces the fatigue life, fastens crack propagation, and reduces fatigue threshold (Mars \& Fatemi, 2002).

In contrast, effects of seawater (or water in general) on NR fatigue have not been investigated to the same extent as in air. Mott and Roland (2001) carried out accelerated ageing experiments and found that the concentration of oxygen in seawater has a direct effect on degradation of NR. As for fatigue behavior, under relaxing loading conditions $(R=0)$, one 
study suggests that fatigue crack propagation rates are almost identical to the ones in air (Selden 1998). Moreover, after a long-term immersion in seawater of 2.25 years, no difference (compared to air) in crack propagation properties has been observed for $R=0$ (Selden 1998). Additionally, it has been shown that fatigue life under relaxing loading conditions is similar in distilled water (Lake \& Pond 1989) and in seawater (Le Gac et al. 2014) as compared to air. On the other hand, under non-relaxing loading conditions at $R=0.2$, the fatigue threshold is higher and crack propagation is slower in water compared to air regardless of temperature (Legorju-Jago \& Bathias 2002). In a recent study by Le Gac et al. (2014), a decrease in fatigue life is observed in seawater compared to air under non-relaxing loading conditions; this result is obtained for filled NR (15 phr of carbon black) with and without antioxidants. Moreover, it appears that antioxidant leaching has no effect on fatigue life of NR in seawater (Le Gac et al. 2014).

In the present paper, the focus is primarily on the first two factors, mechanical loading and the environment. Since fatigue properties of NR are relatively well understood in air, the objective is to compare these properties in seawater; an important question is whether the vast knowledge of fatigue behavior in air can be expanded to the seawater environment. The present work parallels the study of Le Gac et al. (2014), specifically, to a greater range of deformation levels under which the beneficial effects of strain-induced crystallization are greatly enhanced. Both fatigue life and fatigue crack propagation experiments are carried out, and the corresponding damage mechanisms are observed by scanning electron microscopy (SEM). 


\section{EXPERIMENTAL PROGRAM}

\subsection{MATERIAL}

The composition of the studied material is given in Table 1 . The material is molded into sheets of $2 \mathrm{~mm}$ uniform thickness and the specimens are cut using a die and a pneumatic press. The experiments are performed on a virgin material and no pre-aging steps are considered.

Table 1: Material composition.

\begin{tabular}{ll} 
INGREDIENTS & AMOUNT (phr) \\
& \\
\hline Natural rubber & 100 \\
Carbon black & 45 \\
Sulfur & 1.5 \\
CBS & 1.5 \\
Stearic acid & 2.0 \\
Zinc oxide & 2.5 \\
6PPD & 2.0
\end{tabular}

\subsection{SPECIMENS}

Fatigue life tests are performed on flat dumbbell specimens (H3) with dimensions shown in Figure 1 (ISO 37:2005 standard, dumbbell: type 3). In the middle of the specimen, the gauge length is $17 \mathrm{~mm}$ long and the stress state is that of uniaxial tension. Fatigue crack propagation tests are performed on single-edge-notched tension (SENT) specimens shown in Figure 2; the dimensions are $146 \mathrm{~mm} \times 25 \mathrm{~mm} \times 2 \mathrm{~mm}$ and a $1 \mathrm{~mm}$ cut is introduced in the middle of the specimen with a brand new blade. The design of the experimental grips reduces the effective length of $\mathrm{H} 3$ and SENT specimens to $28 \mathrm{~mm}$ and $96 \mathrm{~mm}$ respectively. 


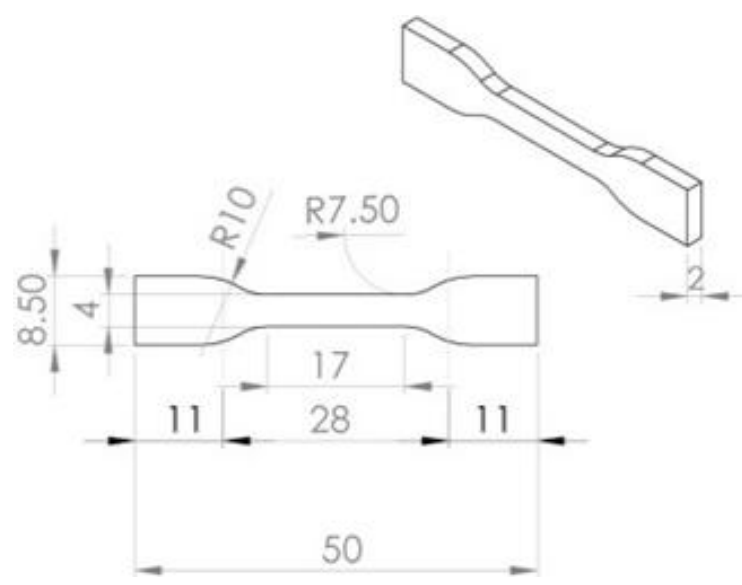

Figure 1: Dimensions of $\mathrm{H3}$ specimen used for fatigue life tests.

Figure 2: Dimensions of SENT specimen used for crack propagation tests.

\subsection{EXPERIMENTAL PROCEDURE}

Actual fatigue tests are performed on custom-built electrically driven machines (actuators Parker PRA 3810S). The testing machines apply a sinusoidal waveform that is displacement controlled. The sinusoidal movement of the actuators is verified manually (minimum and maximum positions) and by using an LVDT. Tests are performed in both air and seawater environments. The loading ratios $R=0$ and $R=0.2$ are considered. These values are calculated considering the local maximum stretch ratio $\lambda_{\text {local }}$. All fatigue experiments are performed at 
2.0 Hz. Experiments in air are carried out at laboratory room temperature, i.e. $22^{\circ} \mathrm{C}$. For the experiments in seawater, specimens are submerged into home-made tanks ( $12 \mathrm{~L}$ in volume). The seawater is extracted directly from the roadstead of Brest and its properties are shown in Table 2. Seawater is continuously renewed by slow drainage and addition of extra seawater; the rate of water flow through the tank is in the order of magnitude of $1 \mathrm{~L} / \mathrm{h}$, which does not affect the temperature that is held constant at $25^{\circ} \mathrm{C}$ by using a thermocouple-controlled heater. Water is aerated and its closed circulation is managed by a pump. The seawater is replaced for each test. The experimental setup for fatigue life tests is shown in Figure 3.

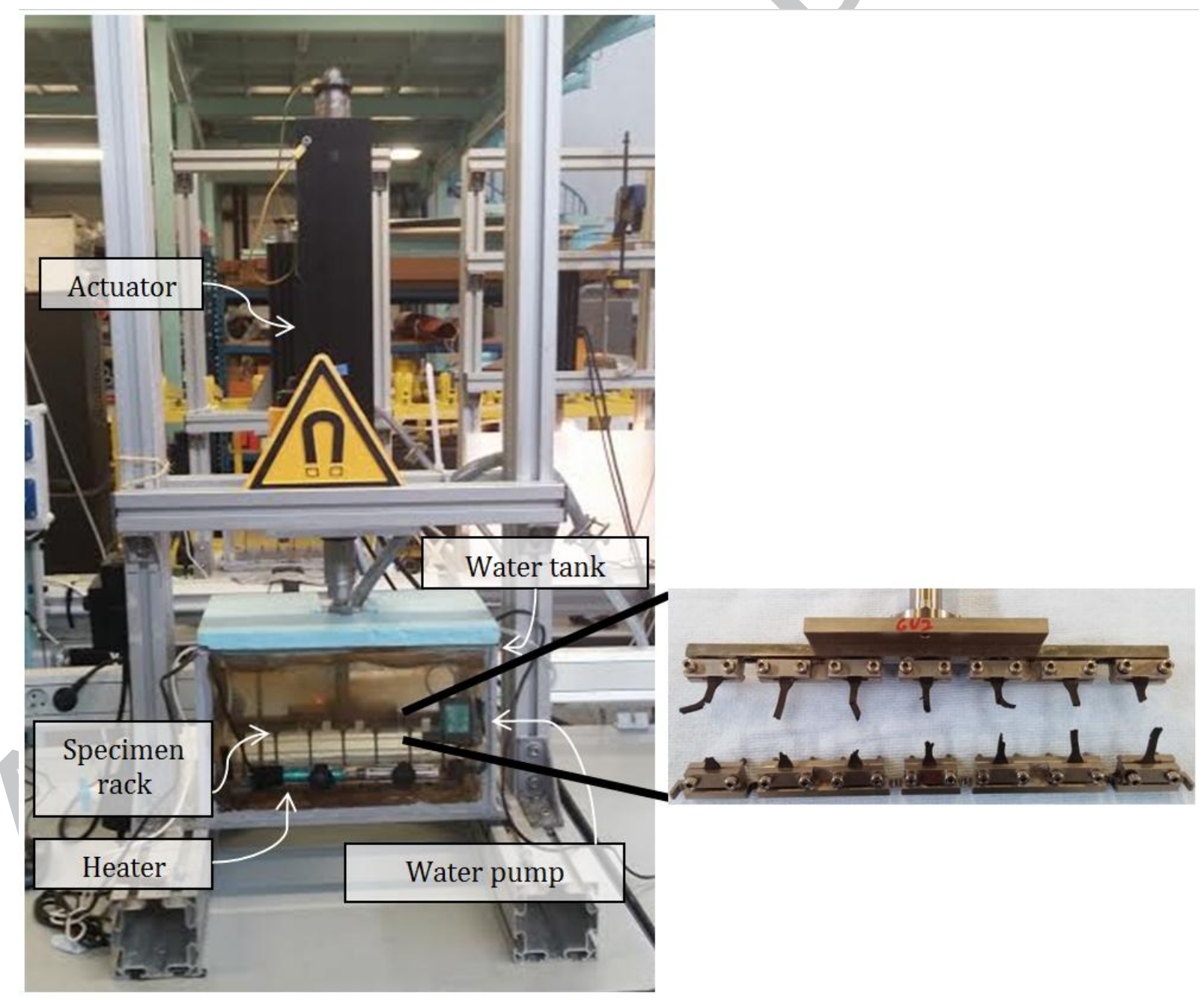

Figure 3: Experimental setup for fatigue life tests in seawater (for experiments in air, the tests are performed on the same setup but without water); magnified is the design of the grips. 
Before the fatigue experiments, the Mullins effect is removed by performing 50 cycles at $110 \%$ of the maximum local stretch ratio prescribed in fatigue experiments. The frequency of these accommodation cycles is set to $0.5 \mathrm{~Hz}$ and a 15 min long relaxation period is imposed between accommodation and start of the fatigue experiments.

Table 2: Seawater properties (data provided by SOMLIT http://somlit-db.epoc.u-bordeaux1.fr/bdd.php).

\begin{tabular}{l|cc} 
& MIN & MAX \\
\hline TEMPERATURE (C & \multicolumn{2}{|c}{25.00} \\
SALINITY (PSU) & 34.40 & 35.13 \\
OXYGEN CONTENT (mL/L) & 5.44 & 6.47 \\
pH & 7.96 & 8.11
\end{tabular}

\subsubsection{PRELIMINARY TESTS}

The maximum local stretch ratio $\lambda_{\text {local }}$ differs from the prescribed global stretch ratio due to sample geometry. Here, the local stretch ratio is measured by digital image correlation (DIC). The material's stress-strain response and the details of the DIC experiments are expanded in Appendix A. Additionally, experiments are carried out to measure the heat build-up of the $\mathrm{H} 3$ specimens in air. The average temperatures of the surface of the specimen are recorded using an infrared thermometer for given maximum stretch ratios $\lambda_{\text {local }}=1.5,2.0,2.5,3.0$ and 4.15 at a frequency of $2 \mathrm{~Hz}$.

\subsubsection{FATIGUE LIFE}

For fatigue life experiments, the end-of-life criterion is defined as the number of cycles until complete failure of the specimen. Experiments are carried out at constant stretch ratio amplitudes $\Delta \lambda=\lambda_{\max }-\lambda_{\min }=1.0,1.5,2.0$, and 2.5 , for $R=0$ and $R=0.2$; values for maximum and minimum applied stretch ratios are shown in Table 3. The corresponding displacements prescribed to the testing machines are calculated from the DIC results. Special home-made grips allowed to test up to 7 specimens per single experiment. With fatigue life testing of 
rubbers in general, there is usually a high dispersion of results due to presence of preexisting microscopic flaws of inhomogeneous sizes (Mars \& Fatemi 2003, Li et al. 2015). Therefore, for statistical significance, at least 14 specimens are tested for each loading level at $R=0$ and $R=0.2$ in each environment.

Table 3: Maximum and minimum applied stretch ratios for each fatigue life test level.

\begin{tabular}{c|rr|cc} 
& \multicolumn{2}{|c|}{$\mathbf{R = 0}$} & \multicolumn{2}{c}{$\mathbf{R = 0 . 2}$} \\
\hline $\begin{array}{c}\text { LEVEL/ } \\
\text { AMPLITUDE }\end{array}$ & $\begin{array}{c}\text { MIN. LOCAL } \\
\text { STRETCH }\end{array}$ & $\begin{array}{c}\text { MAX. LOCAL } \\
\text { STRETCH }\end{array}$ & $\begin{array}{c}\text { MIN. LOCAL } \\
\text { STRETCH }\end{array}$ & $\begin{array}{c}\text { MAX. LOCAL } \\
\text { STRETCH }\end{array}$ \\
\hline $\mathbf{1 :} \boldsymbol{\lambda}_{\mathrm{a}}=\mathbf{0 . 5 0}$ & 0 & 1.50 & 1.13 & 1.63 \\
$\mathbf{2 :} \boldsymbol{\lambda}_{\mathbf{a}}=\mathbf{1 . 0 0}$ & 0 & 2.00 & 1.25 & 2.25 \\
$\mathbf{3 :} \boldsymbol{\lambda}_{\mathrm{a}}=\mathbf{1 . 5 0}$ & 0 & 2.50 & 1.38 & 2.88 \\
$\mathbf{4 :} \boldsymbol{\lambda}_{\mathbf{a}}=\mathbf{2 . 0 0}$ & 0 & 3.00 & 1.51 & 3.51 \\
$\mathbf{5 :} \boldsymbol{\lambda}_{\mathbf{a}}=\mathbf{2 . 5 0}$ & 0 & 3.50 & 1.65 & 4.15
\end{tabular}

\subsubsection{FATIGUE CRACK PROPAGATION}

Crack propagation experiments are performed at low and high stretch ratio amplitudes in order to measure crack growth rates for a wide range of tearing energies. Due to testing machine constraints, the prescribed amplitudes vary from $\Delta \lambda=0.3$ to $\Delta \lambda=0.7$ for both loading ratios; values for maximum and minimum applied stretch ratios are shown in Table 4. The tearing energy of the SENT specimen is approximately related to the crack length $c$ and the strain energy density $W$ by (Rivlin \& Thomas 1953):

$T=2 k W c$

where $k \cong \pi / \sqrt{\lambda}$ (Lindley 1972). The value of $W$ is measured experimentally as the total area under the stress-strain curve after accommodation cycles (Rivlin \& Thomas 1953). Experiments are run continuously at constant amplitudes until fracture of the specimen and the crack length is recorded by a high speed camera. However, during experiments under $R=0.2$, crack branching occurs where secondary cracks are formed and their growth direction is not perpendicular to the loading direction. In such cases, a test is stopped if crack branching 
occurs for crack lengths greater than half of the width of the SENT specimen; if crack branching occurs for crack lengths less than half of the width of the specimen, the test is paused and a new notch is cut along the original path of the crack in the direction perpendicular to the direction of loading. Crack propagation rate measurements are made only after the fatigue blunting of the new notch.

Table 4: Maximum and minimum applied stretch ratios for each crack propagation test level.

\begin{tabular}{r|cc|cc} 
& \multicolumn{2}{|c|}{$\mathbf{R}=\mathbf{0}$} & \multicolumn{2}{c}{$\mathbf{R}=\mathbf{0 . 2}$} \\
\hline $\begin{array}{c}\text { LEVEL/ } \\
\text { AMPLITUDE }\end{array}$ & $\begin{array}{c}\text { MIN. LOCAL } \\
\text { STRETCH }\end{array}$ & $\begin{array}{c}\text { MAX. LOCAL } \\
\text { STRETCH }\end{array}$ & $\begin{array}{c}\text { MIN. LOCAL } \\
\text { STRETCH }\end{array}$ & $\begin{array}{c}\text { MAX. LOCAL } \\
\text { STRETCH }\end{array}$ \\
\hline $\mathbf{1 :} \boldsymbol{\lambda}_{\mathbf{a}}=\mathbf{0 . 1 0}$ & 0 & 1.10 & 1.03 & 1.13 \\
$\mathbf{2 :} \boldsymbol{\lambda}_{\mathbf{a}}=\mathbf{0 . 2 0}$ & 0 & 1.20 & 1.05 & 1.25 \\
$\mathbf{3 :} \boldsymbol{\lambda}_{\mathbf{a}}=\mathbf{0 . 3 0}$ & 0 & 1.30 & 1.07 & 1.37 \\
$\mathbf{4 :} \boldsymbol{\lambda}_{\mathbf{a}}=\mathbf{0 . 4 0}$ & 0 & 1.40 & 1.10 & 1.50 \\
$\mathbf{5 :} \boldsymbol{\lambda}_{\mathbf{a}}=\mathbf{0 . 5 0}$ & 0 & 1.50 & 1.12 & 1.62 \\
$\mathbf{6 :} \boldsymbol{\lambda}_{\mathbf{a}}=\mathbf{0 . 6 0}$ & 0 & 1.60 & 1.15 & 1.75 \\
$\mathbf{7 :} \boldsymbol{\lambda}_{\mathbf{a}}=\mathbf{0 . 7 0}$ & 0 & 1.70 & N/A & N/A
\end{tabular}

\subsubsection{DAMAGE MECHANISM ANALYSIS}

JEOL JSM-6060LA scanning electron microscope (SEM) is used for microscopic analysis of specimens tested for fatigue life. The fractured specimens and those obtained from interrupted tests are considered; the interrupted tests are carried out at stretch amplitude $\Delta \lambda=1.5$ and $R=0.2$ in both air and seawater. All specimens are stretched up to $\lambda=1.3$ using a Deben micro-tensile machine in order to open cracks and defects during observations. Additionally, Energy Dispersive Spectroscopy (EDS) is used to inspect the chemical composition of surfaces around and within the cracks by keeping the electron beam stationary on several points for localized information. 


\section{RESULTS}

\subsection{FATIGUE LIFE}

The fatigue life results are shown on a Wohler curve, where the fatigue life (number of cycles to failure) in both environments is plotted with respect to the stretch amplitude $\Delta \lambda$ (Figure 4). The geometric averages of fatigue lives with their $95 \%$ confidence intervals are presented for each testing condition. The equation for calculation of $95 \%$ confidence intervals is the following:

$C_{95}= \pm t_{95} \frac{s}{\sqrt{n}}$

where $s$ is the estimated standard deviation, $n$ is the number of tested specimens, and $t_{95}$ is the upper (1-0.95)/2 critical value for a T-Distribution (since the true standard deviation is not known) with $n-1$ degrees of freedom. Because testing of 14 specimens for each testing condition in each environment provides statistical significance, small differences in the fatigue life results can be discussed.

In general, the fatigue life decreases as stretch ratio amplitude increases for both relaxing $(R=0)$ and non-relaxing $(R=0.2)$ loading conditions. The average fatigue lives and the corresponding $95 \%$ confidence intervals in seawater and in air significantly overlap under relaxing loading conditions $(R=0)$. For all loading levels, it is clear that the fatigue lives are identical in both environments.

As expected, under non-relaxing loading conditions $(R=0.2)$, the fatigue life increases in both environments. Moreover, the average fatigue life at $\Delta \lambda=0.5$ decreases by around $7 \%$ in seawater as compared to air with a considerable overlap of the confidence intervals. At $\Delta \lambda=1.0$, the average fatigue life in seawater decreases by around $21 \%$ as compared to air within the boundaries of confidence intervals. The average fatigue life at $\Delta \lambda=1.5$ in seawater 
increases by around $6 \%$, but also with a considerable overlap of the confidence intervals. Finally, the fatigue life in seawater is revealed to be longer than in air for large stretch ratio amplitudes (an increase of around $66 \%$ at $\Delta \lambda=2.0$ and $77 \%$ at $\Delta \lambda=2.5$ ).

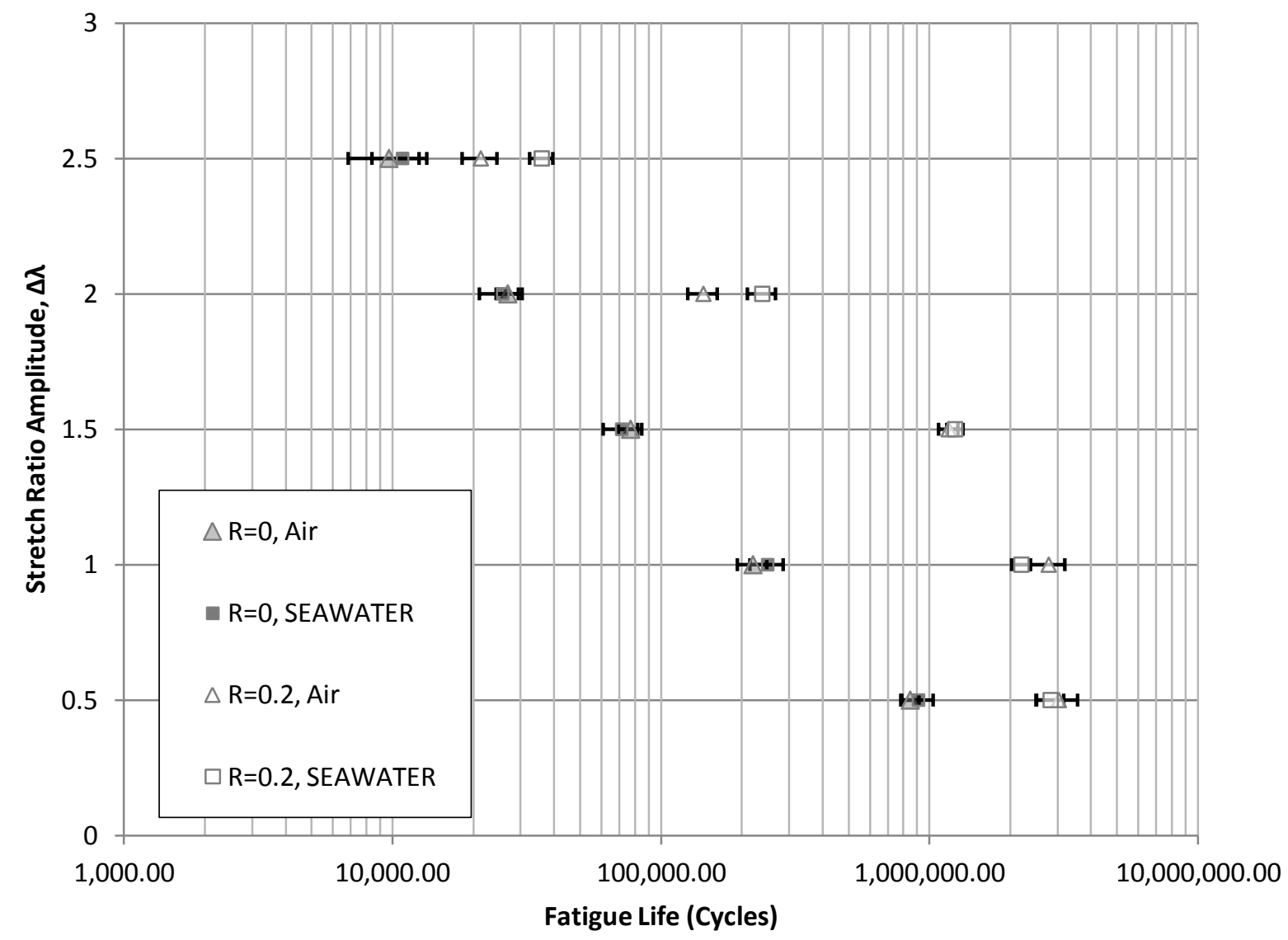

Figure 4: Fatigue life of NR in seawater and air at $R=0$ and $R=0.2$.

\subsection{FATIGUE CRACK PROPAGATION}

The fatigue crack propagation results are shown in Figure 5, where the crack propagation rate is plotted with respect to the tearing energy. The crack propagation rate is identical in seawater and air under both loading conditions, $R=0$ and $R=0.2$. Moreover, the crack propagation rate under non-relaxing loading conditions is slower and the fatigue threshold increases in both seawater and air in comparison to relaxing loading conditions. It should be 
noted that crack branching is observed during experiments under non-relaxing loading conditions (Figure 6).

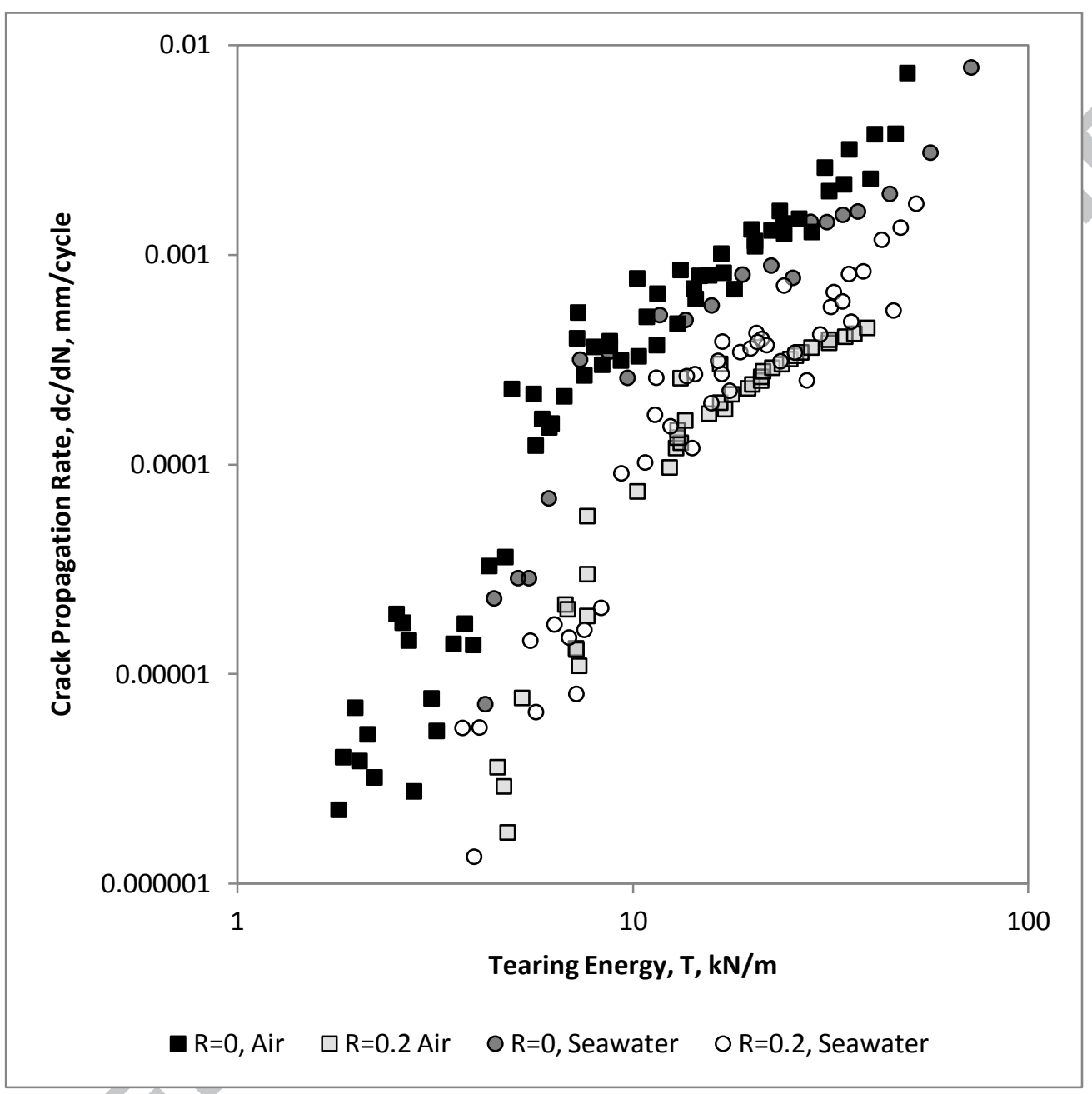

Figure 5: Fatigue crack propagation rate of $\mathrm{NR}$ in sweater and air at $R=0$ and $R=0.2$. 


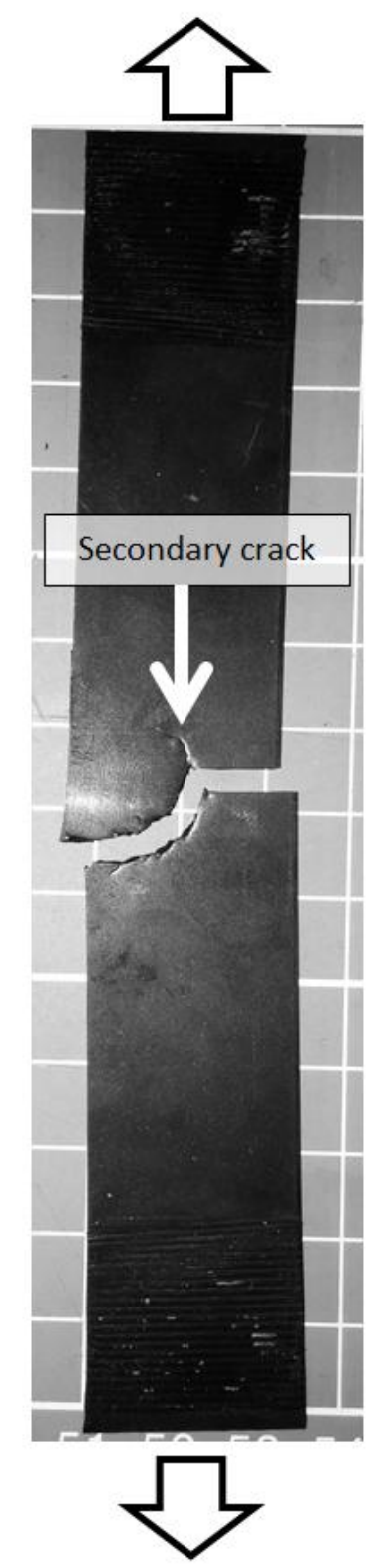

Figure 6: Example of crack branching under $R=0.2$ loading of a SENT specimen (direction of loading is vertical).

\subsection{DAMAGE MECHANISM ANALYSIS}

Surfaces of specimens tested for fatigue life are inspected using scanning electron microscopy (SEM) (Figures 7-12). Microscopic damage features are similar irrespective of the stretch ratio amplitude and the environment for relaxing loading conditions $R=0$ (Figure 7). Cracks form on a plane perpendicular to the loading direction and their lengths vary from 
$100 \mu \mathrm{m}$ to $500 \mu \mathrm{m}$. Crack densities on the surface increase with stretch ratio amplitude in a similar manner for both environments.

a)
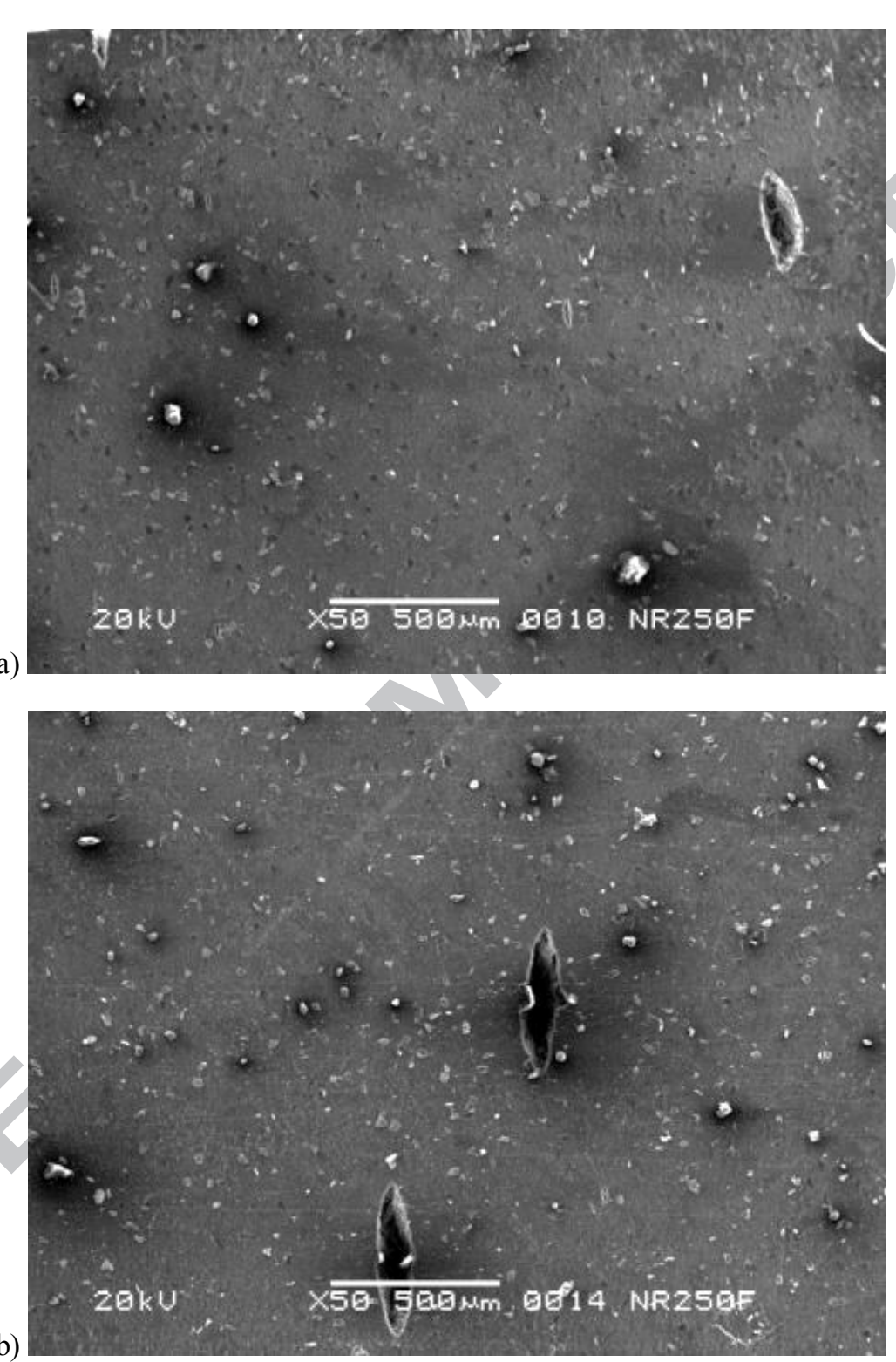

Figure 7: SEM micrographs in a) air and b) seawater under relaxing loading conditions; horizontal direction of loading; failed specimen stretched at $\Delta \lambda=1.5$.

Under non-relaxing loading conditions $(R=0.2)$, morphology of cracks differs between air and seawater. In air, cracks appear on a plane perpendicular to the loading direction (Figure 8a). Damage in seawater is completely different. Cracks appear in form of a cross on the surface and two cones form an "hourglass-shape" in 3D; qualitatively speaking, the majority 
of such cracks are symmetric with only few cracks appearing in form of a half of an "hourglass." Energy Dispersive Spectroscopy does not identify in the matrix any foreign inclusions such as oxides or other poorly dispersed compound ingredients within cracks. The difference in the damage mechanisms is also revealed by edge cracks. In seawater, the direction of crack growth is parallel to the loading direction, and both crack branching and secondary cracks are observed (Figure 9b). However in air, the cracks are mostly uniform and develop on a plane perpendicular to the loading direction (Figure 9a). Moreover, a high density of microscopic cracks (inferior to $100 \mu \mathrm{m}$ in length) is observed on specimens tested in air, but similar features do not appear in seawater (Figure 10). 
a)
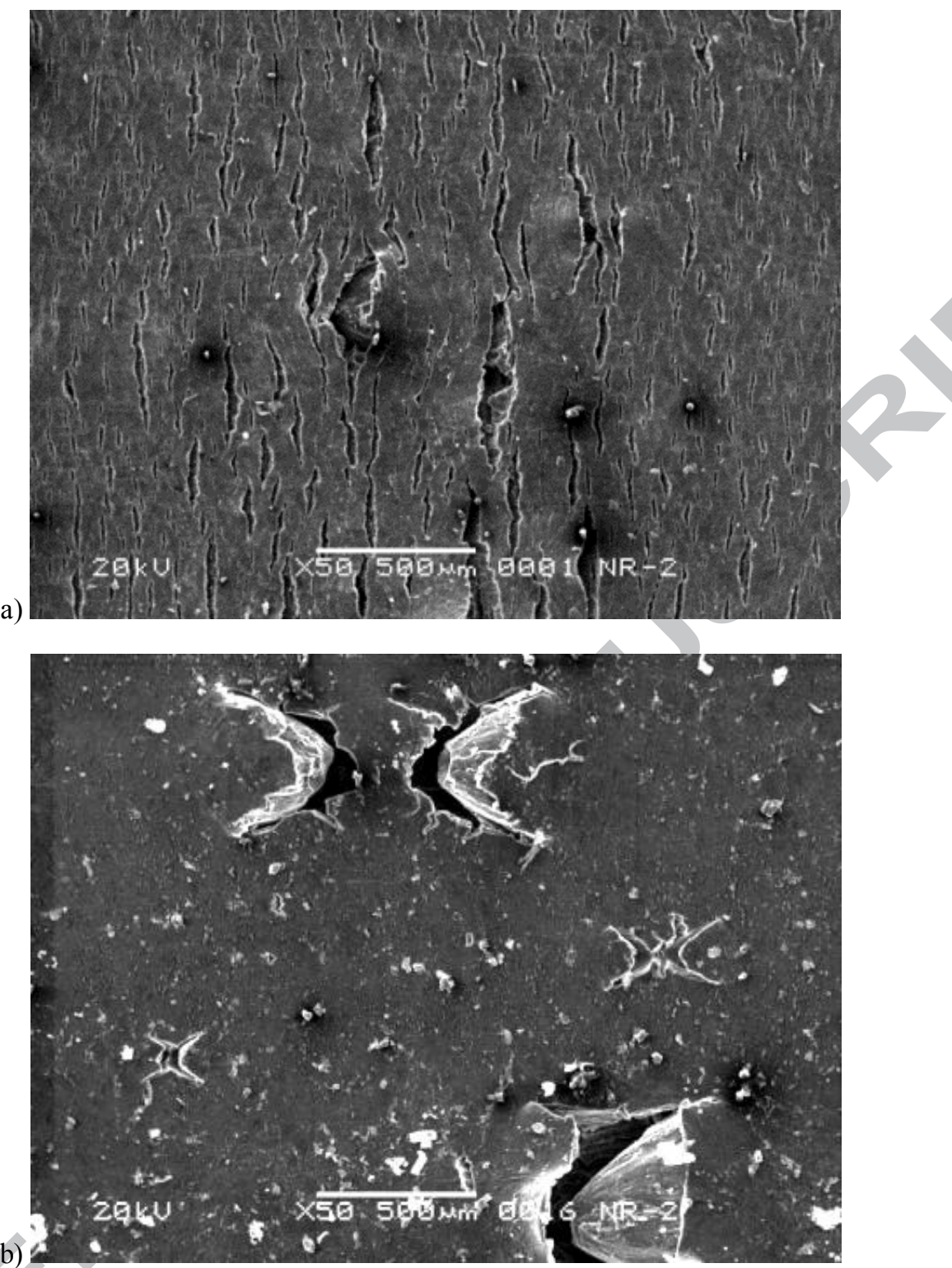

Figure 8: SEM micrographs in a) air and b) seawater under non-relaxing loading conditions; horizontal direction of loading; interrupted specimen stretched at $\Delta \lambda=1.5$. 
a)

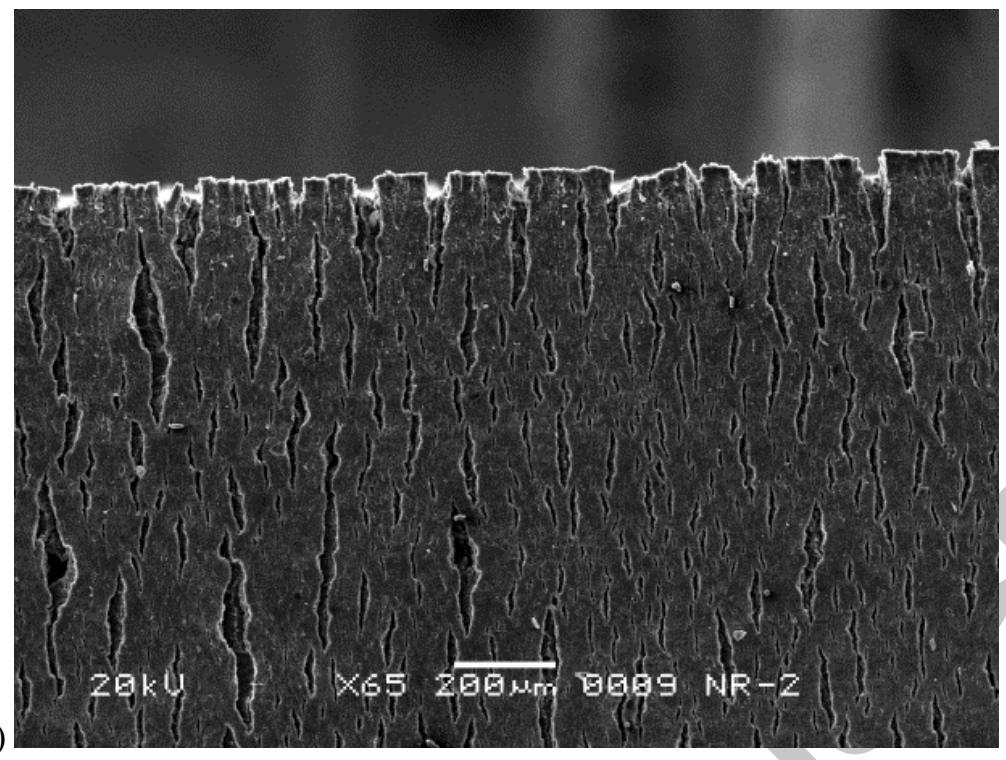

b)

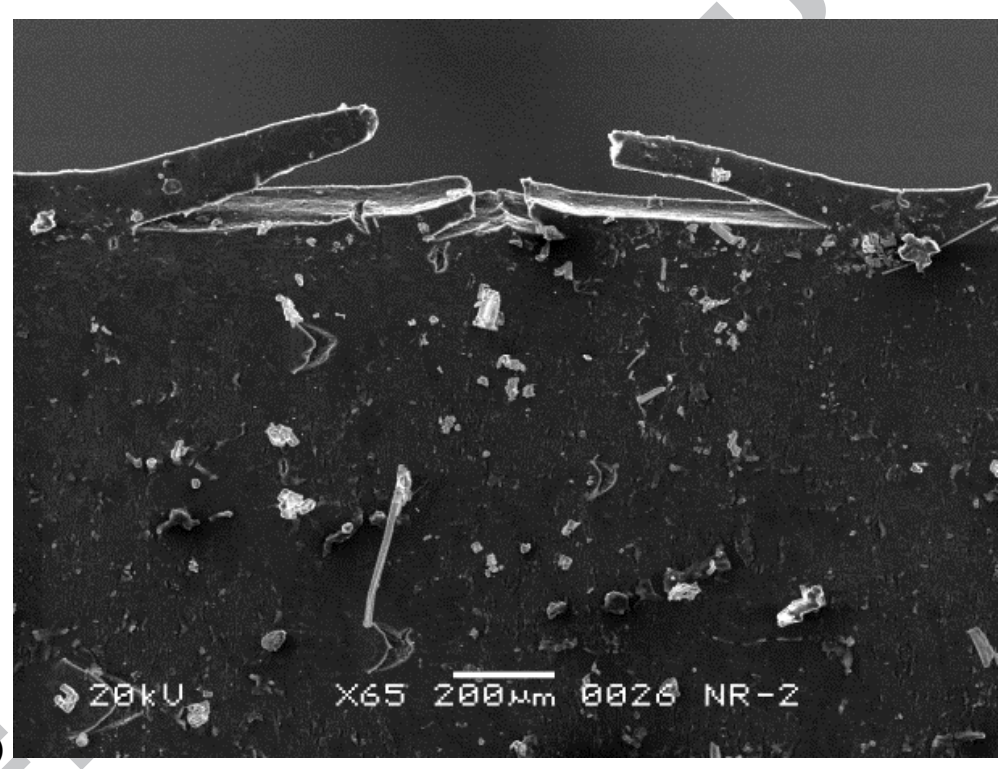

Figure 9: SEM micrographs of edges in a) air and b) seawater under non-relaxing loading conditions; horizontal direction of loading; interrupted specimen loaded at $\Delta \lambda=1.5$. 


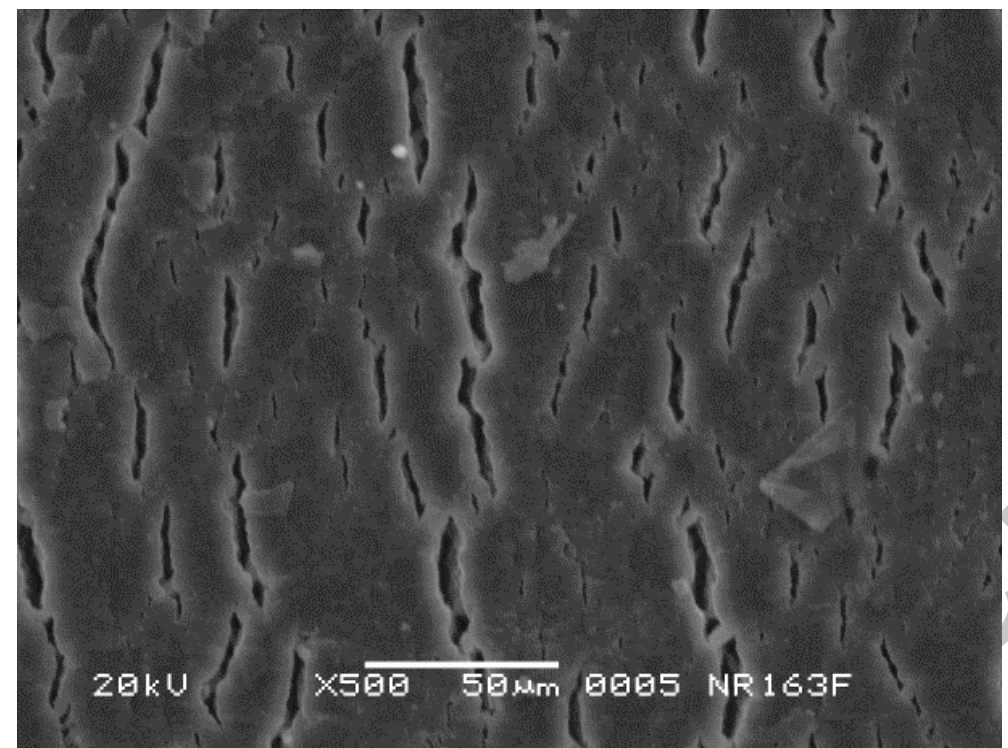

Figure 10: Small cracks on the surface of a specimen tested in air at $R=0.2$; horizontal direction of loading; failed specimen loaded at $\Delta \lambda=0.5$.

Additionally, the effect of the stretch amplitude under non-relaxing loading conditions is shown in Figures 11 and 12. The crack morphology depends on both the stretch ratio amplitude and the environment. In seawater, crack paths on the surface evolve from smooth curves at lower stretch ratio amplitudes (Figure 11a) to more irregular ones at higher ones (Figure 11b). In air, the crack morphology is similar for low (Figure 12a) and high (Figure 12b) amplitudes with only difference in their densities: the number of cracks of all sizes increases as the stretch ratio amplitude increases. 
a)
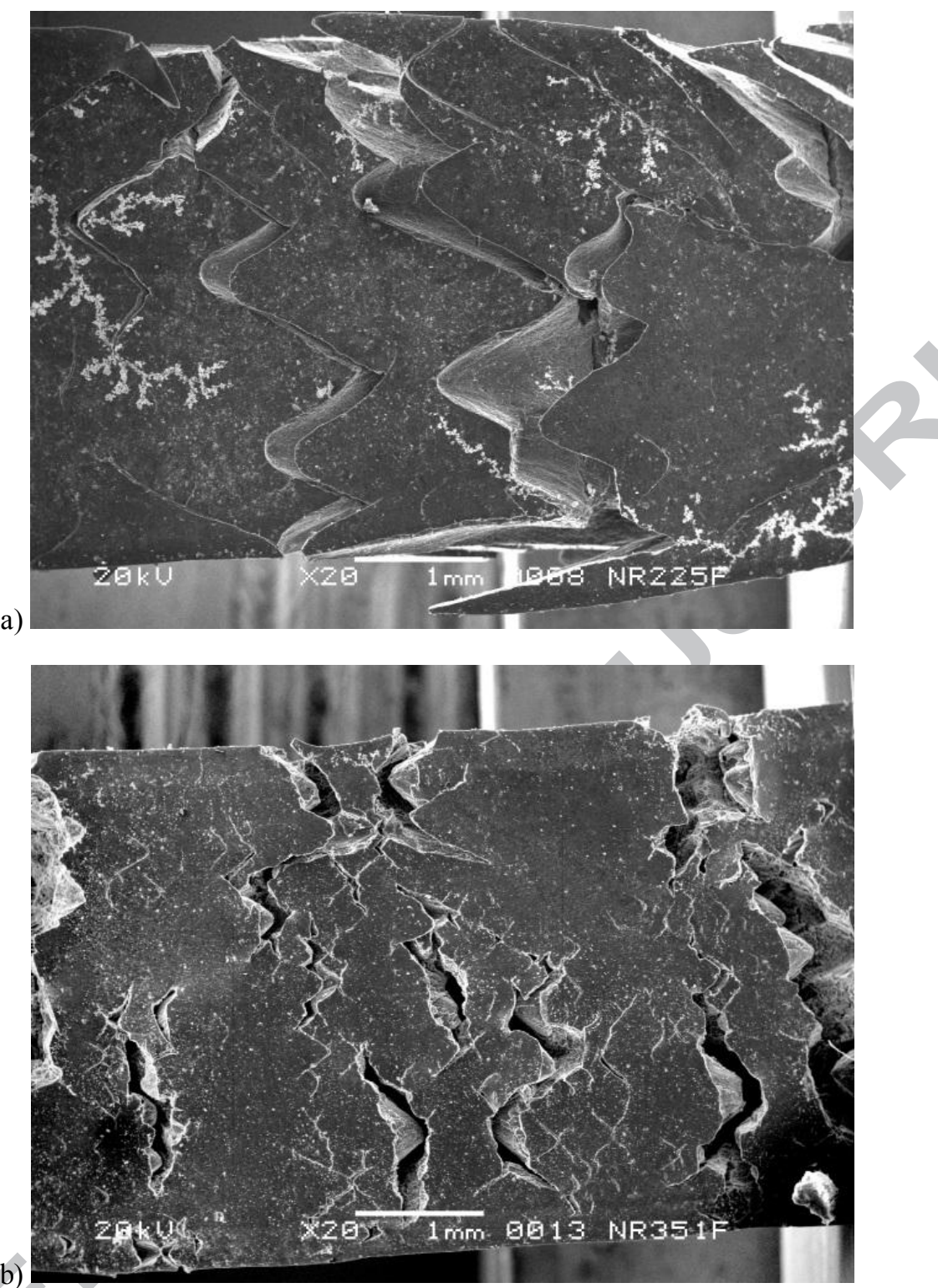

Figure 11: SEM micrographs in seawater under non-relaxing loading conditions at a) $\Delta \lambda=1.0$ and b) $\Delta \lambda=2.0$; horizontal direction of loading; taken at failure. 


\section{a)}
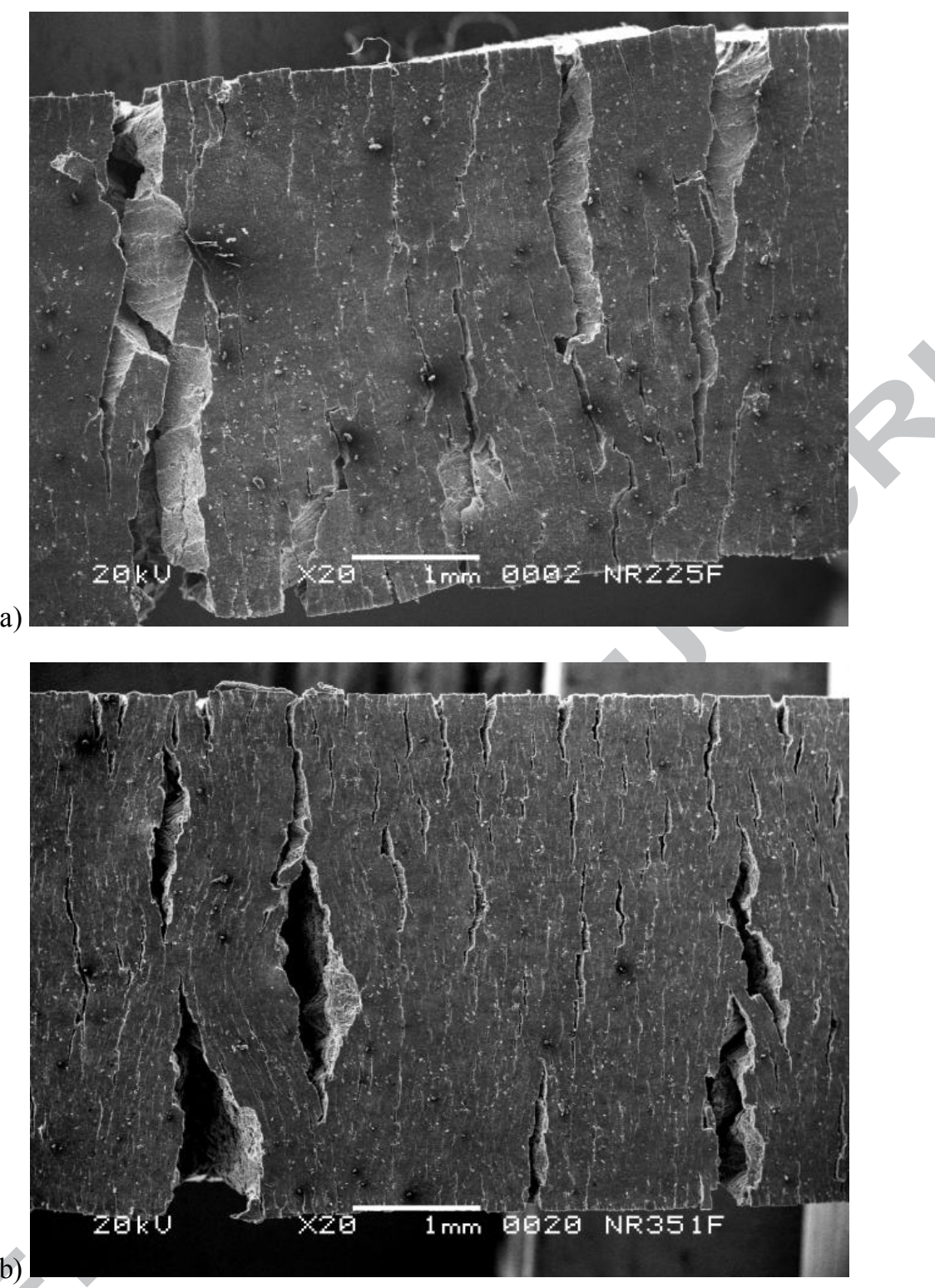

Figure 12: SEM micrographs in air under non-relaxing loading conditions at a) $\Delta \lambda=1.0$ and b) $\Delta \lambda=2.0$; horizontal direction of loading; taken at failure. 


\section{DISCUSSION}

\subsection{Relaxing loading conditions}

Under relaxing loading conditions $(R=0)$, the three experimental approaches reveal with significant correlation that the fatigue behavior of NR is similar in seawater and in air. Primarily, fatigue lives are the same in both environments for all stretch ratio amplitudes. Moreover, these results agree with those of Le Gac et al. (2014). Secondly, the crack propagation behavior is also identical in both environments; likewise, this is in agreement with literature (Selden 1998). Thirdly, the damage mechanisms observed by SEM are the same in both environments; cracks in seawater and air are perpendicular to the direction of loading. Thus, it appears that NR fatigue properties under relaxing loading conditions are not affected in a positive or negative manner by seawater in comparison to the properties in air.

\subsection{Non-relaxing loading conditions}

On the other hand, the results under non-relaxing conditions $(R=0.2)$ are not as clear-cut. The results highlight a considerable improvement of fatigue lives and reduction of crack growth rates at $R=0.2$ in comparison to $R=0$ loading conditions for both air and seawater. Therefore, it is sensible to first discuss the overall effect of the $R$-ratio separately from the effect of the environment.

\subsubsection{Effect of positive $R$-ratio irrespective of the environment}

As mentioned in the introduction, it is widely accepted that improved fatigue properties of NR for $R>0$ are due to increased presence of SIC in NR. It is now well-established that under quasi-static loading conditions, strain-induced crystallites appear at a given threshold stretch ratio (for $50 \mathrm{phr}$ carbon black content, it varies from around 2.0 to 2.4); moreover during unloading, the crystallites melt at a smaller threshold stretch ratio, which for filled NR is close to the above-mentioned crystallization stretch ratio (Trabelsi et al. 2003, Beurrot-Borgarino et 
al. 2013, Candau et al. 2015a). It should be noted that these threshold values change with both temperature and strain rate (Candau et al. 2015c). Thus, no precise values of these quantities will be given in the following discussion. As a consequence, the influence of SIC on fatigue properties depends on both minimum and maximum cyclic stretch ratios, and thus on the $R$ ratio: number of studies have demonstrated that fatigue life increases as $R$-ratio increases (Cadwell et al. 1940, André et al. 1999, Saintier et al. 2006) mainly because fatigue crack growth is retarded (Lindley 1973, Legorju-Jago \& Bathias 2002, Mars \& Fatemi 2003, Saintier et al. 2011, Rublon et al. 2014). This hypothesis is supported by the results of crack propagation experiments. In initial observations, there is the occurrence of crack branching due to SIC under non-relaxing loading conditions (Figure 6). Since the crystalline regions at the crack tips are significantly larger and induce an anisotropic microstructure (Hamed et al. 1999, Saintier et al. 2011, Rublon et al. 2014), the symmetry around the crack disappears and the crack branches out with growth proceeding in a path not perpendicular to the direction of loading. This observation is reinforced by the experimental results, where the crack propagation rate is slower and the fatigue threshold is generally higher for $R=0.2$ as compared to $R=0$.

However, the positive effect of non-relaxing loading conditions differs in regards to the stretch ratio amplitude. For $R=0.2$ loading, the relative increase of fatigue life observed between the results for $\Delta \lambda=1.0$ and those for $\Delta \lambda=0.5$ (with respective maximum stretches of $\lambda_{\max }=2.25$ and $\left.\lambda_{\max }=1.63\right)$ is almost negligible considering the large decrease in the stretching level. The incidence of SIC and its beneficial effects are reduced for $\Delta \lambda=0.5$ in comparison to $\Delta \lambda=1.0$; it can be explained by the relative position of the loading conditions with respect to the above-mentioned crystallization and melting thresholds (BeurrotBorgarino et al. 2013, Candau et al. 2015d). 
For higher stretch ratio amplitudes $(\Delta \lambda \geq 1.5)$, there are however three competing phenomena. First, the material reinforces due to the increase in crystallinity during cyclic loading. Nevertheless, it is counteracted by the effect of large loading, which promotes damage and therefore shortens fatigue life. The third phenomenon is the increase of heat build-up due to high stretch ratio amplitudes, which also greatly contributes to deterioration in fatigue properties (Young 1986, Legorju-Jago \& Bathias 2002). These three factors explain why the positive effect of R-ratio on fatigue life diminishes with increasing strain levels for $\Delta \lambda \geq 1.5$

\subsubsection{Effect of the seawater environment in comparison to air}

Due to these different behaviors at low and large stretch ratio amplitudes, the effect of seawater on fatigue properties under non-relaxing loading conditions is now discussed in the two next sections

\subsubsection{Low stretch ratio amplitudes}

For $\Delta \lambda=0.5,1.0$ and 1.5, fatigue lives in seawater and air are close and within the $95 \%$ confidence intervals. Although, the experimental methods of the present work differ to those of Le Gac et al. (2014), a comparison of the results can be performed. Loading conditions considered in Le Gac et al. parallel the low stretch ratio amplitudes investigated in the present work (Figure 13). At first glance, the results of Le Gac et al. and of the present work could appear different: Le Gac et al. observe a tangible difference in fatigue life in both environments. However, some parallels are noticeable upon closer inspection of the present results. The average fatigue lives are shorter in seawater than in air within the stretch ratio amplitude range $\Delta \lambda=0.5-1.0$ : the difference in fatigue life is about $7 \%$ with a significant $98 \%$ overlap of the confidence intervals for $\Delta \lambda=0.5$ and, for $\Delta \lambda=1.0$, it is about $26 \%$ with a $22 \%$ overlap of the confidence intervals. However, in the present work, the fatigue lives (in both 
air and seawater) are longer. These discrepancies between the two studies are explained by different experimental methods: most importantly, the material formulations are different. The longer fatigue lives of the present work can be explained because the present material has a higher $\mathrm{CB}$ content (45 phr vs $15 \mathrm{phr}$ ). With reference to the earlier discussion in Section 4.2.1., the stretch ratio thresholds at which crystallization appears and melts depends on filler content; these thresholds are higher for NR with carbon black content of $15 \%$ as compared to 45\% (Trabelsi et al. 2003, Rublon 2013, Candau et al. 2015a). As such, the beneficial influence of SIC is greater in the present work under the effects of non-relaxing loading conditions.

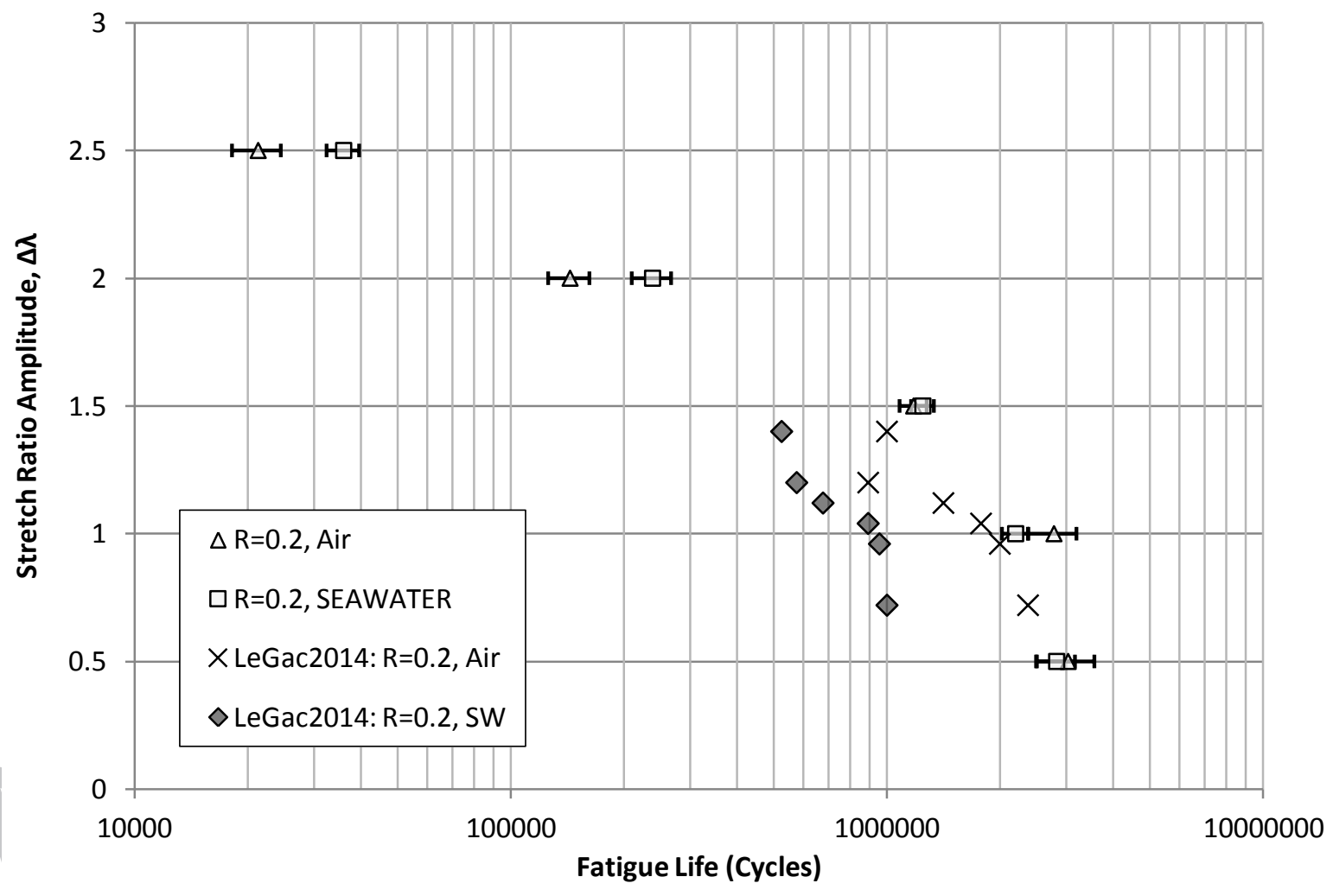

Figure 13: $R=0.2$ fatigue life results in seawater and air compared to the results of Le Gac et al. (2014).

Now, considering that the fatigue crack propagation is the same in both environments, it suggests that crack nucleation and subsequent growth occur slightly earlier in seawater for 
low stretch ratio amplitudes. It is difficult to give a precise explanation for this phenomenon.

Le Gac et al. suggest that the decrease in fatigue life could be attributed to reduced presence of SIC in seawater. Another explanation can be proposed: the influence of air (oxygen) on the formation of multiple micro-cracks on the surface of the specimens as shown in Figure 10; these micro-cracks appear at all stretch ratio amplitudes on specimens tested in air, but are absent on those tested in seawater. We argue that the energy available for crack growth is distributed amongst all these micro-cracks, thus retarding the emergence of a main crack which causes the failure. Obviously, this phenomenon should not be taken into account at the very end of fatigue life when crack coalescence takes place.

\subsubsection{Large stretch ratio amplitudes}

For stretch ratio amplitudes $\Delta \lambda=2.0$ and 2.5 fatigue lives are longer in seawater than in air (these amplitudes are larger than those considered in Le Gac et al.) Compared to the low stretch ratio amplitudes, the principal differences are: a higher incidence of SIC due to the increase in the minimum stretch ratio $\lambda_{\min }$; and higher specimen temperatures in air than in seawater due to heat build-up of NR. Indeed, as mentioned above, seawater temperature is held constant at $25^{\circ} \mathrm{C}$; thus, it can be argued that the surface temperatures of seawater tested specimens are in equilibrium around this temperature because of high heat conductivity of seawater. Conversely, air is a much poorer conductor of heat (lower by a factor of about 30 as compared to seawater) and therefore, for the largest stretch ratio amplitude the surface temperature in air is measured to be about $35^{\circ} \mathrm{C}$. As noted previously, the fatigue life shortens and crack propagation rates increase at elevated temperatures. This argument does not contradict fatigue crack propagation results. Indeed, the temperature of SENT specimens in air is not as large as the one in $\mathrm{H} 3$ because of a smaller prescribed stretch ratio and a larger surface area of the SENT specimens; thus crack propagation results are the same in both environments and they do not correlate to the fatigue life tests measured for large stretch ratio 
amplitudes. Additionally, the incidence of SIC in NR highly depends on temperature: as it increases, the onset of crystallization is shifted toward higher values of $\lambda$ and the total levels of crystallinity decrease (Albouy et al. 2005). To confirm the hypothesis of the deleterious effect of heat build-up in air, supplementary fatigue life experiments are carried out for these large stretch ratio amplitudes, under the same testing conditions, and in both environments at a lower frequency of $0.5 \mathrm{~Hz}$. This reduces the temperature in air-tested specimens; however, the temperature of the water-tested specimens remains around $25^{\circ} \mathrm{C}$ (the temperature of seawater) because of higher heat conductivity. The hypothesis is confirmed with the fatigue life being the same in both environments. With these explanations, it is possible to rationalize the longer fatigue life in seawater as compared to the one in air for large stretch ratio amplitudes.

In regards to scanning electron microscopy, the damage observed in air under nonrelaxing loading conditions is typical to that of oxygen/ozone ageing, where numerous cracks are present and are perpendicular to the direction of loading (Figure 8a). In contrast, the damage in seawater is noticeably different (Figure 8b); these observations are original and have not been encountered in literature. More so, the mechanisms behind this type of damage are unknown. It should be noted that no inclusions have been detected by EDS and, as such, do not appear to be responsible for the initiation of the cracks. At first glance, if one considers only one half of the symmetric "hourglass" cracks, it could appear to resemble decohesion at the poles due to presence of $\mathrm{CB}$ agglomerates (Huneau et al. 2016). Consequently, the presence of symmetry would imply formation of cracks in exact pairs, i.e. initiation of these cracks due to a pair of CB agglomerates, which is highly unlikely. Moreover, conical shaped crack induced by $\mathrm{CB}$ agglomerates has not been reported in the literature. Therefore, initiation due to carbon black agglomerates can also be excluded. 
In seawater, the morphology of edge cracks is indicative of the effects of SIC (Figure 9b), where the cracks propagate in the direction parallel to the direction of loading. This is analogous to the crack branching phenomenon observed during fatigue crack propagation experiments under non-relaxing conditions. Additionally, the increased irregularity of crack paths at larger stretch ratio amplitudes in seawater is also characteristic of crack branching and, accordingly, is indicative of a large presence of local crystallinity (Figure 11b). The absence of such branching at larger stretch ratio amplitudes in air supports the hypothesis that the incidence of SIC is reduced under high internal temperatures of the specimens (Figure 12). 


\section{CONCLUSIONS}

Three experimental techniques are applied to study the fatigue properties of NR in seawater under both relaxing and non-relaxing loading conditions: fatigue life and crack propagation experiments, and SEM analysis. Results show that the NR fatigue properties in seawater are identical to that in air under relaxing loading conditions $(R=0)$. For non-relaxing loading conditions $(R=0.2)$, where increased beneficial effects of strain-induced crystallization are observed, the fatigue behavior in seawater differs from that in air. At small stretch ratio amplitudes $(\Delta \lambda=0.5,1.0,1.5)$, the fatigue life are very close in seawater and in air. However, the fatigue life is longer in seawater than in air for large stretch ratio amplitudes $(\Delta \lambda=2.0$ and 2.5). Heat build-up of specimens at large stretch ratio amplitudes appears to have significant influence on the properties: because of thermal properties of seawater, temperatures of specimens in seawater are lower than temperatures of the ones tested in air. Degradation of fatigue properties at high temperatures could be attributed to the reduction of the beneficial effects of SIC in such conditions. This conclusion is supported by the damage observed in seawater and air for $R=0.2$ loading conditions. The damage mechanisms in seawater appear to be unique and are not fully understood. However, increased presence of crack branching in seawater and its relative absence in air points to reduction of SIC in specimens tested in air for large stretch ratio amplitudes and high temperatures.

\section{ACKNOWLEDGEMENTS}

The authors would like to thank P. Guégan and F. Pasco of Ecole Centrale de Nantes, and M. Premel-Cabic of Ifremer for their assistance during experimental campaign. 


\section{Appendix A}

The contents of Appendix A are related to the uniaxial mechanical behavior of the present material as obtained from tensile tests and digital image correlation (DIC). Before tensile testing, the specimens are preconditioned for 50 cycles.

The stress-strain experimental data is shown in Figure A.1.

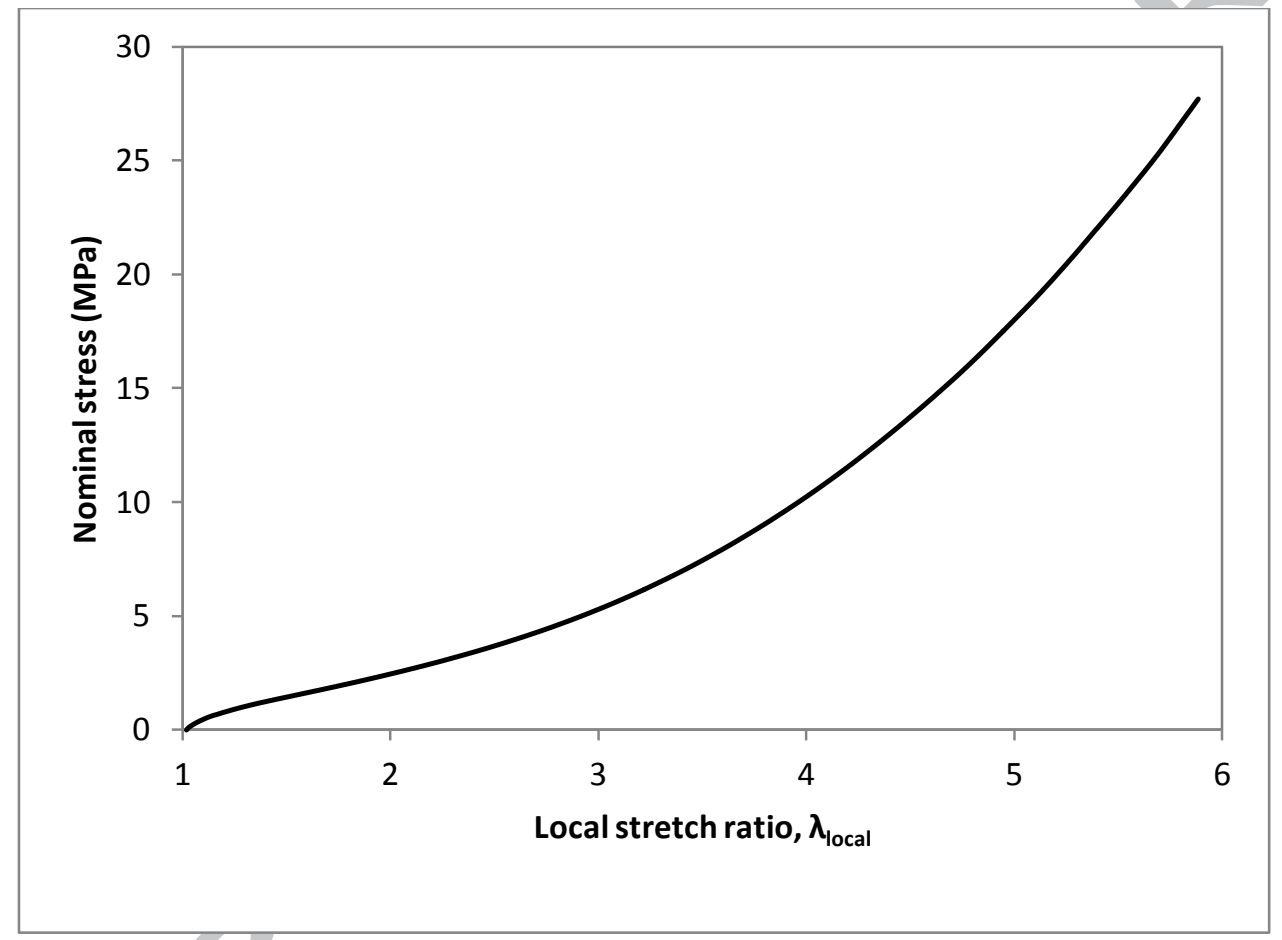

Figure A.1: Uniaxial stress-stain behavior of the tested material.

Digital image correlation is used to find the relationship between the global and the maximum local stretch ratios. Commercial software Vic2D is used to measure the local stretch ratio; after calibration, the software automatically calculates the Hencky strain on a speckled specimen. The magnitude of the Hencky strain is related to the local stretch ratio by the following equation:

$$
\varepsilon_{H}=\ln \left(\frac{l}{l_{0}}\right)=\ln (\lambda)
$$


The results of DIC analysis show a linear correlation between local and global stretch ratios for both $\mathrm{H} 3$ and SENT specimens (Figure A.2).
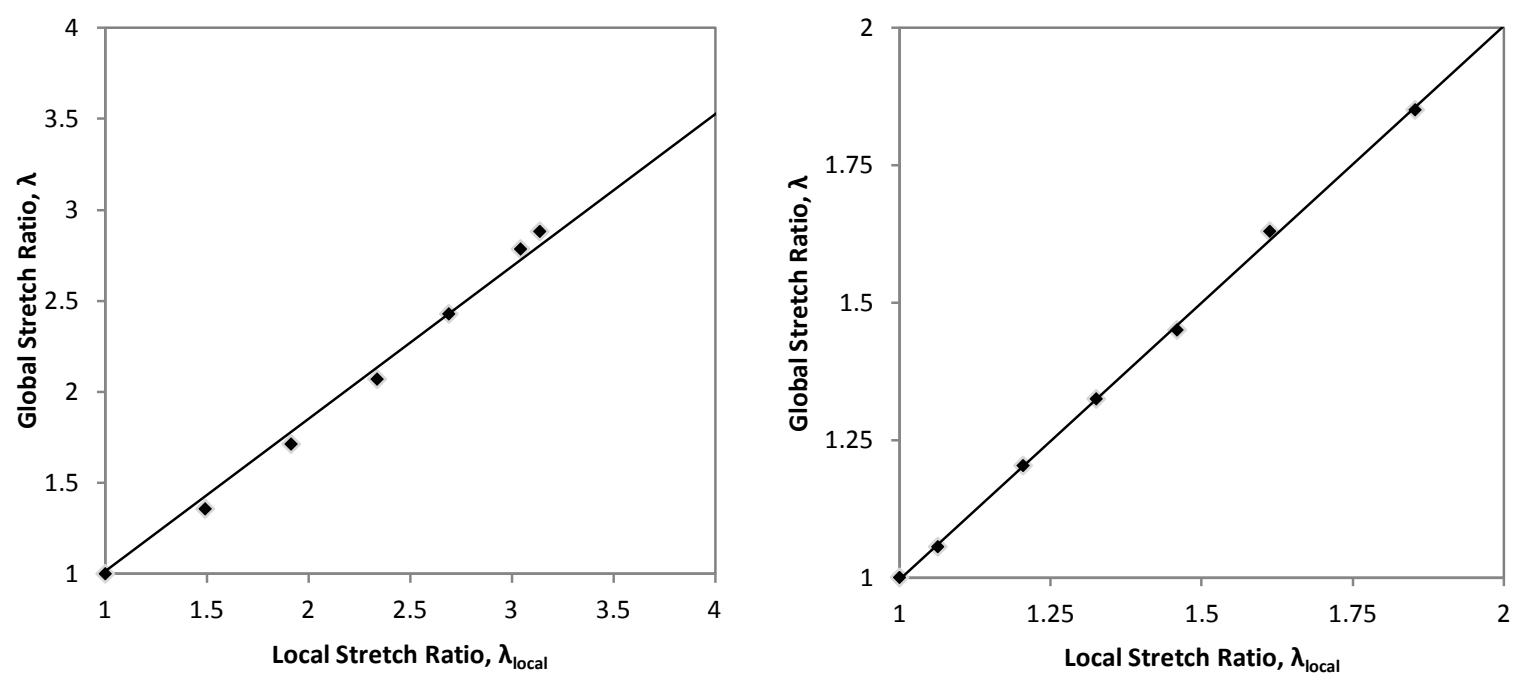

Figure A.2: Relationship between the maximum local and global stretch ratios for H3 (left) and SENT (right) specimens. 


\section{REFERENCES}

1. Mars, W. \& Fatemi, A. 2002. A literature survey on fatigue analysis approaches for rubber. International Journal of Fatigue 24: 949-961.

2. Mars, W. 2004. Factors that affect the fatigue life of rubber: a literature survey. Rubber Chemistry and Technology 77: 391-412.

3. Beatty, J. 1964. Fatigue of Rubber. Rubber Chemistry and Technology 37(5): 1341-1364.

4. Lindley, P.B. 1973. Relation between hysteresis and the dynamic crack growth resistance of natural rubber. International Journal of Fracture 9(4): 449-462.

5. Gent, A.N. \& Zhang, L.-Q. 2002. Strain-induced crystallization and strength of rubber. Rubber Chemistry and Technology 75(5): 923-933.

6. Tosaka, M. 2007. Strain-Induced Crystallization of Crosslinked Natural Rubber As Revealed by X-ray Diffraction Using Synchrotron Radiation. Polymer Journal 39: 12071220.

7. Huneau, B. 2011. Strain-Induced Crystallization of Natural Rubber: A Review of X-Ray Diffraction Investigations. Rubber Chemistry and Technology 84(3): 425-452.

8. Cadwell, S., Merrill, R., Sloman, C., Yost, F. 1940. Fatigue Life of Rubber. Industrial and Engineering Chemistry, Analytical Edition 13: 19-23.

9. Rivlin, R. \& Thomas, A. 1953. Rupture of rubber. I. Characteristic energy for tearing. Journal of Polymer Science 10(3): 291-318.

10. Lindley, P.B. 1972. Energy for crack growth in model rubber components. Journal of Strain Analysis 7: 132-140.

11. Lake, G. 1995. Fatigue and fracture of elastomers. Rubber Chemistry and Technology 68: 435-460.

12. Lake, G. \& Lindley, P.B. 1965. The Mechanical Fatigue Limit for Rubber. Journal of Applied Polymer Science 9: 1233-1251. 
13. Legorju-Jago, K. \& Bathias, C. 2002. Fatigue initiation and propagation in natural and synthetic rubbers. International Journal of Fatigue 24: 85-92.

14. Gent, A. \& Hindi, M. 1990. Effect of Oxygen on the Tear Strength of Elastomers. Rubber Chemistry and Technology 63: 123-134.

15. Datta, R. \& Huntink, N. 2000. Rubber Vulcanizates Degradation and Stabilization. Rubber Chemistry and Technology 80: 435-480.

16. Selden, R. 1998. The Effect of Water Immersion on Fatigue Crack Growth of Two Engineering Rubbers. Journal of Applied Polymer Science 69: 941-946.

17. Lake, G. \& Pond, T. 1989. Effects of aqueous environments on fatigue and elastic properties of rubber. Polymers in a Marine Environment: 141-147.

18. Le Gac, P., Arhant, M., Davies, P., Muhr, A. 2014. Fatigue behaviour of natural rubber in marine environment: comparison between air and seawater. Materials and Design 65: 462467.

19. Mars, W. \& Fatemi, A. 2003. Fatigue crack nucleation and growth in filled natural rubber. Fatigue Fracture Engineering Material Structures 26: 779-789.

20. Li, F., Liu, J., Mars, W. Chan, T., Lu, Y., Yang, H., Zhang, L. 2015. Crack precursor size for natural rubber inferred from relaxing and non-relaxing fatigue experiments. International Journal of Fatigue 80: 50-57.

21. Trabelsi, S., Albouy, P.-A., Rault, J. 2003. Effective local deformation in stretched filled rubber macromolecules. 36(24): 9093-9099.

22. Beurrot-Borgarino, S., Huneau, B., Verron, E., Rublon, P. 2013. Strain-induced crystallization of carbon black-filled natural rubber during fatigue measured by in situ synchrotron X-ray diffraction. International Journal of Fatigue 47: 1-7. 
23. Candau, N., Chazeau, L., Chenal, J., Gauthier, C., Munch, E. 2015a. Compared abilities of filled and unfilled natural rubbers to crystallize in a large strain rate domain. Composite Science and Technology 108: 9-15.

24. Rublon, P. 2013, Etude expérimentale multi-échelle de la propagation de fissure de fatigue dans le caoutchouc naturel (in French). PhD Thesis: Ecole Centrale de Nantes.

25. Candau, N., Laghmach, R., Chazeau, L., Chenal, J., Gauthier, C., Biben, T., Munch, E. 2015c. Influence of strain rate and temperature on the onset of strain induced crystallization in natural rubber. European Polymer Journal 64: 244-252.

26. Andre, N., Cailletaud, G., Piques, R. 1999. Haigh diagram for fatigue crack initiation prediction of natural rubber components. Kautschuk und Gummi Kunststoffe 52(2): 120123.

27. Saintier, N., Cailletaud, J., Piques, P. 2006. Multiaxial fatigue life prediction for a natural rubber. International Journal of Fatigue 28(5-6): 530-539.Saintier, N., Cailletaud, J., Piques, P. 2011. Cyclic loadings and crystallization of natural rubber: An explanation of fatigue crack propagation reinforcement under a positive loading ratio. Materials Science and Engineering A 528: 1078-1086.

28. Rublon, P., Huneau, B., Verron, E., Saintier, N., Beurrot, S., Leygue, A., Mocuta, C., Thiaudière, D., Berghezan, D. 2014. Multiaxial deformation and strain-induced crystallization around a fatigue crack in natural rubber. Engineering Fracture Mechanics 123: 59-69.

29. Candau, N., Laghmach, R., Chazeau, L., Chenal, J., Gauthier, C., Biben, T., Munch, E. 2015d. Strain induced crystallization and melting of natural rubber during dynamic cycles. Physical Chemistry Chemical Physics 17(23): 15331-15338. 
30. Young, D. 1986. Fatigue Crack Propagation in Elastomer Compounds: Effects of strain rate, temperature, strain level and oxidation. Rubber Chemistry and Technology 59: 809825.

31. Albouy, P.A., Marchal, J., Rault J. 2005. Chain orientation in natural rubber, Part I: the inverse yielding effect. The European Physical Journal. E, Soft matter 17(3): 247-59.

32. Hamed, G. R. \& Kim, H. J. 1999. Cut growth in vulcanizates of natural rubber, cispolybutadiene, and a 50/50 blend: Part II. Cracking patterns in the strained state. Rubber Chemistry and Technology 72(5): 895-909.

33. Huneau, B., Masquelier, I., Marco, Y., Le Saux, V., Noizet, S., Schiel, C. \& Charrier, P. 2016. Fatigue crack initiation in a carbon black-filled natural rubber. Rubber Chemistry and Technology 89(1): 126-141. 